\title{
Areas of the Competence of Reason in the Teachings of Al-Ghazali
}

\author{
Maythem Al-Janabi \\ Peoples' Friendship University of Russia (RUDN \\ University) \\ 6 Miklukho-Maklaya St., Moscow, 117198, Russian \\ Federation \\ E-mail:m-aljanabi@mail.ru
}

\author{
Nur Kirabaev \\ Peoples' Friendship University of Russia (RUDN \\ University) \\ 6 Miklukho-Maklaya St., Moscow, 117198, Russian \\ Federation \\ E-mail: kirabaev@gmail.com
}

\begin{abstract}
New methodological approaches to studying the philosophical heritage of al-Ghazali (1058-1111) are connected with the understanding of another culture as "a different culture and logic of thinking," the Arab-Muslim culture as a "phenomenon of cross-cultural interaction, the role of "the ideal of knowledge and cognitive attitude to reality" In the Muslim tradition. The article shows that the teaching of alGhazali on the relationship between faith and reason is the key to understanding the integrity of his teaching, within which existing antinomies show the regulative role of reason in philosophy and science, the possibility of subordinating theoretical reason to the practical, as well as the practical significance of his theory of the supermind In Sufism.
\end{abstract}

Keywords-reason; supermind; faith; knowledge; action; philosophy; "theology"; philosophers-peripatetics; falsafa; kalam; Sufism

\section{INTRODUCTION}

An understanding of the relationship between reason and faith in various philosophical traditions should not only take into account, but proceed from the body of dogmatic and legal establishment of a particular religion and, on the whole, be based on the rules and principles of the correlation of philosophy and theology in each specific historical epoch. In some formulations, this relationship has always been one of the central problems of ontology and the theory of knowledge, ethics and aesthetics, social philosophy, including free-thinking and attitude to religious authorities.

It seems that it was the separation of spiritual, intellectual, and social and political activities that caused conflict and clashes between "philosophical reason" and "incontrovertible codes" of religion. Thus, with the necessity arises the unity of opposites, because the "critical-analytic" activity of the mind is not separated from the "iron curtain" from its own apologetic, protective abilities, and the limitations of dogmatics contain elements of completely rational regulation of thoughts and feelings. The mind cannot be isolated from other regulators of a particular type of culture, it does not restrain its internal transformation, rethinking its postulates, and the limitations of the dogmatic legal establishment are

This publication was supported by the Ministry of Education and Science of the Russian Federation (the Agreement number 02.A03.21.0008 not so narrow that it does not fit the task of its internal transformation within the rational interpretation of the dogmas of religion, Otherwise it would be impossible to talk about theology. Thus, the establishment of faith is nothing but a mind historically transformed in the form of indisputable "sacred commandments".

It should be noted that the question posed by al-Ghazali and his predecessors about the relationship between reason and faith is only a "historical-Muslim" formulation of the general cultural problem engendered by the course of political and spiritual-intellectual confrontation in the caliphate. This problem faced the thinkers of different cultures and civilizations. Comparison of the world of Islam with the world of Christianity shows that the problems solved in the Muslim and Christian culture arose in a concrete historical context. Consequently, each of them has a special cultural face. It is the Arab-Muslim culture, on the one hand, that allows us to talk about the tradition of continuity of pre-Islamic culture, and, on the other hand, to consider it as a result of cross-cultural interaction. It is important to bear in mind that the ideological "childhood" is no less difficult than the ideological "old age", because the latter forgets the "suffering" of the first.

\section{FAITH AND REASON IN THE ARAB-MUSLIM TRADITION}

The question of the relationship between reason and the establishment of faith in the Arab-Muslim philosophy had its political and spiritual-intellectual prehistory. This question has been the focus of attention for no one generation. The search for a solution to this problem was, as it were, suffered in religious and socio-political collisions and discussions, which resulted in a special way of interpreting and rational interpretation of "sacred Scripture" in the context of political interests and religious ideology.

III. THE TEACHING OF AL-GHAZALI ON THE DELINEATION OF THE SPHERES OF COMPETENCE OF REASON AND FAITH

Al-Ghazali attempted in the first of his major theologicalphilosophical works, "Tahafut al falasifa (The Incoherence 
of the Philosophers), to show the world-wide significance of the main problems of philosophy. This gave him the opportunity to formulate elements of critical polemic with representatives of the Falsafa in order to identify what he called "Incoherence", including with regard to the issue of attitude toward the establishment of faith. Therefore, it would be wrong to consider the criticism of the "mind of peripatetic" as a rejection of rationalism, or as evidence that al-Ghazali himself took the establishment of faith in the quality of the supreme arbiter. It can be said that al-Ghazali stood against the forced introduction of reason into the world of artificial analogies and interpretations, for such an approach to reason is purely subjective and does not have a reasonable basis and value. Here, he clearly stands on the position of delimiting the spheres of competence of reason and faith.

However, this does not mean that al-Ghazali proposed or formulated the concept of "duality of truth" (dogmatic-legal and philosophical-rational), although at first his judgments contained some elements of such a concept. He repeatedly stressed that faith does not force to disagree with the rationalistic conclusions of philosophers and scientists on the problems of science and its exact constrictions. Therefore, the controversy that appears in the "Tahafut al falasifa (The Incoherence of the Philosophers)" as directed against the mind is in fact nothing more than a theological-philosophical formulation of reasonable skepticism directed against the socalled "four major divergences", which are the subject of many pages of this work (problems of causality, soul, eternity of the soul, resurrection and judgment day).

So, the negative attitude of al-Ghazali to the rationalism of peripatetic philosophers is expressed in the denial of the ability of the mind to make absolute judgments. Proceeding from this, he proposed to consider faith as a different form of reason, an addition to it. In this connection, in particular, he wrote: "We do not object to their approval, ... we just want to clarify, with the example of the resurrection, that it is confirmed by faith. But we deny their assertion that there is enough reason for the proof and it is possible to do without faith" [1. P.206].

The idea of al-Ghazali about the boundaries of the mind and spheres of his competence takes the form of a complete theory in "Ihya' "ulum al-din" (The Revival of the Religious Sciences). And those remarks and ideas that point to the weakness and inability of the mind to find comprehensive answers to all the problems (for example, in such books as "Tahafut al falasifa (The Incoherence of the Philosophers), "al-Iktisad fi al-Iktiad" (Moderation in Dogmas) and partly in "Mizan al-'amal" (The Balance of Action)"), they reflect primarily elements Rational criticism of the mind (theoretical). In this sense, they represent a moderate version of the vision of the real relationship and the possible (abstract) proportion between absolute and relative truth, universal and particular. Consequently, the emergence of the idea of the limitations of the mind reflects one of the levels of its rational and spiritual (moral) development, that is, it reflects one of the forms of overcoming traditional theological rationalism. The essence of this overcoming can be seen not only in the form and manner of the appearance of the problem itself, but also in its content, its social, ethical and cognitive functions.

The connection of al-Ghazali's ideas and judgments about the limitations of reason with the Sufi stage of his intellectual and moral development reflects the nature of the changes and transformations that accompanied the development of theological rationalism in his personal experience. His initial critical position in relation to reason and rationalism acquired the image of total skepticism, dissolved in dialectics and dispute. And in the Sufi period of his work, the idea of the supermind appears as an independent theme, the method and level of knowledge.

The general form of the idea of the limited mind that we find in the "Al-Munqidh min al-dalal (The Deliverer from Error)" is based on his theory of the gradation and unity of knowledge, which found its final embodiment in his ideas about skepticism and scientific certainty. He proceeded from the fact that the refutation by the mind of certain judgments of the sensory perception of the world makes some judgments of the mind itself the object of doubt over the ability of the supermind. Proof of this is the state of the soul during sleep and awakening.

\section{FAITH, DOUBT AND MIND}

At one stage of his intellectual and spiritual development, he confronted the problem of faith, on the one hand, and the problem of doubt in the ability of the mind to uncover the truth and achieve certainty, on the other. If doubt arises, according to al-Ghazali, from the process of cognition itself as a transition and development from sensory perception to imagination, and from imagination to rational understanding, then faith holds on what he called necessary knowledge. The unity of doubt and faith remains always as a substantial motive behind the search for truth as such. Consequently, the recognition of the supermind is a recognition of the infinity of knowledge.

Al-Ghazali, the idea of agnosticism and the impossibility of true knowledge was alien. The essence of this conclusion does not change the presence in his late (Sufi) creativity of such ideas as: no one knows the truth of the poet except the poet himself, the truth of the prophet except the prophet himself, and the substance of God, except God himself. These ideas and statements reflect, first of all, his position on the need for individual cognitive and moral experience as a way of achieving true truth. He left a partial acknowledgment of the existence of a thing in himself, but did not turn this recognition into a certain truth that is beyond the limits of cognition itself and its infinity. In other words, he emphasized the idea of the infinity of knowledge, and not the idea of the impossibility of true knowledge. In this sense, the supermind is both the overcoming of the "limits of the mind" and the new way of knowing the truth beyond the traditional mind.

Speaking about the stages of knowledge, al-Ghazali considered the stage of reason (the third after the sense and ability of discrimination) in a special way in the knowledge of the proper, permissible and impossible things that are not accessible to the first and second levels of knowledge [2. 
P.145]. The mind for al-Ghazali is only one degree and one degree of knowledge. The knowledge of the truth of things is available to the mind as a special method and a special stage, but there is another stage in which "another source opens that can see otherworldly and other kinds of knowledge that are not accessible to the mind just as the abstraction is inaccessible to the second stage of knowledge (the ability to discriminate) And that which is accessible to the second and third stages of knowledge is not available to the senses " [ 2 . P.145]. It follows that his views on the boundaries of the mind proceed from the general epistemological premises that define these boundaries as a boundary in which the mind ceases to know the truth of things as they are. After this, a new facet of cognitive ability arises, which he sometimes calls "prophetic power", sometimes "holy spirit".

The idea of al-Ghazali about the boundaries of the mind is neither irrational nor anti-rational. It is designed to show the limitations of traditional, theologized and formalized reason. He carried out a clear demarcation between what he called the cognitive faculty of the mind and what the mind is unknowable, while that in itself does not lend itself to comprehension, and what we call the limited mind. Saying, for example, about the meaning of resurrection on the basis of the analysis of the divine name "resurrector," he tried to prove that death is not nothingness or nothing, and resurrection is not a re-creation like the first act of divine creation. He considered these problems not in terms of theological and even philosophical reason, but in the criteria of Sufi eating and insight. In other words, the resurrection ceases to be a religious-theological concept, that is, the object of faith, becomes a phenomenal manifestation of the ontological and cognitive being of man. The search for "permanent resurrection" turns into a way of tracking the emergence and development of the body, soul and cognition, including the ascent of the latter to the highest stage [3. P.124].

On the ontological plane, resurrection acquires an abstract form of the development of knowledge from ignorance to knowledge. By this, al-Ghazali himself tried to say that the rational-logical form of knowledge perceives those truths that correspond to its accepted rules, and rejects everything that goes beyond these rules. Using Sufi terminology, al-Ghazali called this approach "the narrowing of divine mercy".

\section{LIMITATION OF REASON}

In the cognitive plane, not everything that the mind cannot comprehend is incomprehensible in itself. And although he considered this statement in the course of analyzing some problems of religious thought, such as the otherworldly life, the general abstract principle contained some rational elements. He tried to prove the necessity of distinguishing between the probable and the impossible in the process of cognition. Hence his statement that faith contains miracles that are probable, but not impossible [4. P. 70]. Limitation of reason, according to al-Ghazali, is determined by his inability to go beyond his own rules. Considering in the "Mishkat al-anwar (The Niche of the Lights)" the problem of the ability of the mind and its essential qualities in comparison with feeling, he tried to show both the ability of the mind and its limitations at the same time. Mind, writes al-Ghazali, realizes himself and others, he is equally remote and close, he even controls everything that is in "the limits of the Throne and the Throne and that behind the Veil" [5. P. 50]. The mind is able to penetrate into the depth and mystery of all things, to recognize their essence and soul, to disclose their causes, how they occur, and what place they occupy in the existent, what their relation to others [5. P. 51]. This means that the mind recognizes not only the essence of things and the causes of their emergence and existence, but their qualitative and quantitative actions, as well as the ability of the mind to control all that is within reality and beyond. Hence the idea of al-Ghazali, that all things are in the area of the mind [5. P. 52]. The ability of the mind to govern and dictate to all things also means its ability to achieve reliable judgment and knowledge of them. The inner secrets are external to him, and the hidden meanings are obvious to him [5. P. 52]. In this sense, the relation of reason to all manifestations of existence is not only speculative in nature, but also the character of authentic knowledge. Accordingly, the mind has no boundaries in the process of cognition. Hence the conclusion of al-Ghazali that this ability of the mind does not contradict the fact of the completeness of the acquired knowledge, for in the forces of the mind an infinite search for knowledge [5. P. 52-53], i e, the idea of a limited mind does not mean the limitations of possible knowledge.

The limitations of the mind, from the point of view of alGhazali, are not an awareness of their own boundaries. This means not recognizing the presence of a different, higher degree of cognition than the intelligence defined by alGhazali as the "veil of reason". All truths, al-Ghazali writes, are not hidden from the mind, but "the veils of reason arise where the mind hides itself" [5. P. 55]. From this it follows that al-Ghazali did not seek to justify the epistemological gap between the levels of cognition. Rather, on the contrary, he tried to justify their internal interpenetration and unity as different levels of light, the brightness of which depends on the level of approximation to the absolute. In The Niche of the World he writes that if the sensory spirit, the spirit of the imagination, the intelligent and theoretical spirits are nothing but different manifestations of light, then it would be correct to say that they are layers of light [5. P. 50]. This approach is designed to justify the possibility of intuitive-reliable knowledge, which is based, in turn, on the dissolved knowledge (Sufi) rational knowledge.

In the "Mishkat al-anwar (The Niche of the Lights)", where he talks about the need to interpret the Sufi words so that they are accepted by the mind [5. P. 116]. An example of this is the idea of the Sufi merger (ittihad). It is not an ontologically existent, for after sobriety, that is, after the return of man to the power of the mind, which is "the divine balance on earth," he realizes that there was only something like merging " [3. P. 156].

\section{CONCLUSION}

From the above, one can come to the conclusion that the degree of al-Wilayat or the level of the supermind does not 
contain anything that could contradict reason and its arguments. At the same time, at this level, something that cannot be achieved solely by reason alone can arise. In other words, there are certain aspects of reliable knowledge that are achieved more quickly with the help of Sufi eating and insight than with reason. He tried to demonstrate this by analyzing the prophecy, where he showed that the negation or rejection of the degree of the supermind is based on ordinary rational reasoning on the basis of its absence. Criticizing this approach in "Ihya' "ulum al-din" (The Revival of the Religious Sciences)" al-Ghazali writes that the absence of a thing cannot serve as an authentic basis for proving its non-existence. Just as ignorance cannot serve as a valid basis for proving its incomprehensibility. Hence his conclusion: "Those who deny the existence of a supermind, rely mainly on the fact that this is either not available to them, or they are not able to reach it" [5. P. 106]. Al-Ghazali described this approach as a complete lack of knowledge, since the supermind, in his opinion, is a way of reliable knowledge, for with its help truth is revealed directly and distinctly. In this sense, the supramental knowledge is the knowledge of authentic intuition, that is, the level that he described in the Deliverer of Delusions as "the level at which the source of knowledge arises in the light of which one can see and understand that which is not available to the mind" [5. P.76].

Al-Ghazali did not seek to transform the supermind into an independent status, which had its own rules of knowledge. He regarded it more as a state in which the theoretical mind dissolves in a "prophetic spirit, for in it all the mysteries of being are revealed and clarified, and also divine knowledge not accessible to the rational and theoretical spirit" [2. P. 146]. Thus, al-Ghazali gave this level of knowledge a special cognitive-ethical character, allowing to consider the unity of reason, theoretical and practical, as well as the unity of knowledge and action.

\section{REFERENCES}

[1] Al-Ghazali. Tahafut al falasifa (The Incoherence of the Philosophers).Cairo, 1972.

[2] Al-Ghazali. Al-Munqidh min al-dalal (The Deliverer from Error), Beirut, Dar al-Andalus. 1976.

[3] Al-Ghazali: al- Maqsad al-Asna fi sharh asma allah al-husna (The high purpose in Explaining the Names of Allah, Beirut, 1987.

[4] Al-Ghazali: al-Madhnun bihi ala gheir ahlihi. (The hidden meaning for others). Dar al-Hikmat. Damascus- Beirut, 1980.

[5] Al-Ghazali: Mishkat al-anwar. The Niche of the Lights Beirut, 1986. 